\title{
INFORMAÇÕES CONTÁBEIS AMBIENTAIS NA PERCEPÇÃO DE ANALISTAS, INVESTIDORES E PROFESSORES DE FINANÇAS
}

\author{
José Alonso Borba \\ Doutor em Controladoria e Contabilidade pela Universidade de São Paulo - USP \\ Professor de Pós-Graduação na Universidade Federal de Santa Catarina - UFSC \\ jalonso@cse.ufsc.br
}

\author{
Thiago Lima Bortoluzzi \\ Bacharel em Ciências Contábeis pela Universidade Federal de Santa Catarina - UFSC \\ tl_bortoluzzi@hotmail.com \\ Jorge Luiz Alves \\ Mestre em Contabilidade pela Universidade Federal de Santa Catarina - UFSC \\ jorge.iessc@gmail.com \\ André Carlos de Souza \\ Mestrando em Contabilidade pela Universidade Federal de Santa Catarina - UFSC \\ a.carlos.souza@hotmail.com
}

\section{RESUMO}

O objetivo deste artigo é analisar a relevância da informação contábil ambiental para a tomada de decisão em investimento de uma companhia, de acordo com a percepção de analistas de investimentos, investidores do mercado de ações e professores das disciplinas de finanças e mercado de capitais. Para tanto, também foi observada a alocação de recursos em uma companhia com evidenciação contábil ambiental favorável em uma companhia com evidenciação contábil ambiental desfavorável. Trata-se de pesquisa exploratória, na qual se utilizam métodos experimentais e abordagem qualitativa. Os dados submetidos à análise dos participantes são de uma companhia do setor de papel e celulose, obtidos no sítio da BOVESPA. Neste processo, cada participante deveria tomar sua decisão sob a seguinte condição: o investimento deve compor a carteira de investimentos de um amigo, destinada a aposentadoria. Os participantes receberam um relatório gerencial e demonstrações contábeis resumidas para apoio à decisão, devendo indicar o valor a ser alocado à companhia analisada (A ou B). Os resultados apresentados indicam que a informação contábil ambiental é relevante, na perspectiva de analistas de investimento, investidores do mercado de ações e professores das disciplinas de finanças e mercado de capitais.

Palavras-chave: Contabilidade ambiental; Experimento; Investimento; Tomada de decisão.

\section{ENVIRONMENTAL ACCOUNTING INFORMATION IN THE PERCEPTION OF ANALYSTS, INVESTORS, AND FINANCE TEACHERS}

\section{ABSTRACT}

The objective of this paper is to analyze the relevance of environmental accounting information for decision-making about investment in a company according to the perception of investment analysts, stock market investors and teachers of finance and capital markets disciplines. We observed resource allocation in a company with favorable environmental accounting disclosure and a company with unfavorable environmental accounting disclosure. This is an exploratory research study, in which we used experimental methods as well as a qualitative approach. The data analyzed was collected from participants from a company in the paper and cellulose sector, obtained at the site of BOVESPA. In this process, participants had to make decisions under the following condition: the investment must make up the investment portfolio of a friend, for retirement. Participants received a management report and summarized financial statements for decision support, and had to indicate the amount to be allocated to the analyzed company (A or B). The results presented that the accounting information environment is relevant from the perspective of analysts, stock market investors, and teachers of finance and capital markets disciplines.

Key words: Decision-making; Environmental accounting; Experiment; Investment. 


\section{INTRODUÇÃO}

O estudo da evidenciação contábil pode ser desenvolvido sob diversas perspectivas. A observação da utilidade da informação evidenciada constitui-se tema recorrente em trabalhos da área de finanças. Nesse sentido, a utilização da informação para o processo de tomada de decisão é tema relevante, na medida em que as políticas de evidenciação influenciam na percepção dos usuários da informação contábil (Deegan, 2002).

Os indivíduos, cuja atuação cotidiana exige a utilização da informação evidenciada pelas companhias, bem como aqueles que a investigam academicamente, estão habituados a identificar qual informação é relevante para a decisão de investimento. Sob um arcabouço predominantemente qualitativo, analisou-se a alocação de recursos a uma companhia, buscando determinar a influência da informação contábil ambiental para a tomada de decisão em investimento.

O tema deste estudo, portanto, é a evidenciação contábil ambiental. A questão central proposta é a seguinte: a evidenciação de informações de natureza ambiental nas demonstrações contábeis ou no relatório da administração influencia na tomada de decisão em investimento em uma companhia?

O objetivo geral deste trabalho consiste em verificar se a evidenciação de informações de natureza ambiental nas demonstrações contábeis ou no relatório da administração influencia na tomada de decisão em investimento em uma companhia na percepção de analistas de investimento, investidores do mercado de ações e professores das disciplinas de finanças e mercado de capitais. Para tanto, desenvolveu-se um caso para análise, por parte dos participantes, elaborado a partir das informações de uma empresa do setor de papel e celulose com ações negociadas na Bovespa. O caso submetido à análise foi concebido a partir do experimento de Alves e Borba (2009). Os sujeitos participantes do experimento são analistas de investimento, investidores do mercado de ações e professores das disciplinas de finanças e mercado de capitais.

Para a consecução do objetivo geral, buscou-se: a) analisar a alocação de recursos realizada por analistas de investimento, investidores e professores das disciplinas de finanças e mercado de capitais a uma companhia com evidenciação contábil ambiental favorável; b) analisar a alocação de recursos realizada por analistas de investimento, investidores e professores das disciplinas de finanças e mercado de capitais a uma companhia com evidenciação contábil ambiental desfavorável; e, c) comparar a alocação de recursos realizada por analistas de investimento, investidores e professores das disciplinas de finanças e mercado de capitais, para as companhias com evidenciação contábil ambiental favorável e desfavorável.

\section{FUNDAMENTAÇÃO TEÓRICA}

Para Hendriksen e Van Breda (1999), fornecer informações para a tomada de decisões é um dos principais objetivos da divulgação financeira. Cho, Roberts e Patten (2010) comentam a propriedade de alterar a percepção dos investidores sobre determinada empresa com base nas informações por ela divulgadas. Para isso, na elaboração dessas informações, são utilizadas determinadas estratégias quanto as características da linguagem utilizada com o objetivo de manipular as decisões e a percepção dos investidores. Alencar e Lopes (2005) comentam que no Brasil, o mercado de ações apresenta características peculiares e que a informação contábil é considerada de grande importância, por conta de, por exemplo, existir uma considerável concentração das ações em poder de um reduzido número de indivíduos, além da influência do Estado na economia.

Nesse cenário sincrético, a informação gerada pela Contabilidade e destinada para os usuários externos, na opinião de Alencar e Lopes (2005), seria de baixa qualidade e, portanto, de utilidade questionável para o processo decisório. O desenvolvimento de estudos para captar a

Revista de Gestão Social e Ambiental - RGSA, São Paulo, v. 6, n. 3, p. 168-182, set./dez. 2012. 
percepção de agentes que atuam nesse mercado pode contribuir para a ampliação do debate nessa área.

\subsection{Informação contábil ambiental}

A abordagem social da Contabilidade é orientada para a divulgação da informação para o maior número possível de interessados. Nesse sentido, o modelo de governança corporativa em que essa divulgação ampla de informações, sugerida por Ferreira (2003), relaciona-se com o modelo stakeholder avançado. Dessa forma, em princípio, a divulgação de informações necessárias à cobertura de eventos relacionados ao meio ambiente não lograria êxito no contexto brasileiro, dada a estrutura limitada do modelo de governança corporativa vigente no Brasil.

Com relação ao interesse do mercado financeiro em informações sociais e ambientais, Murray et al. (2006), em revisão da literatura disponível sobre o tema, ressaltam que: "a) a divulgação ambiental parece ser de maior interesse do mercado financeiro, em detrimento da divulgação social; e, b) a divulgação voluntária é preferível quando se quer emitir sinais ao mercado, e não aquelas evidenciações exigidas de todas as companhias". Por sua vez, Carneiro, Luca e Oliveira (2008) apresentam um estudo segundo o qual as informações ambientais divulgadas por empresas do setor petroquímico, no período de 2004 a 2006, não permitem compreender a forma pela qual essas empresas identificam, mensuram e registram os aspectos ambientais relacionados à sua atuação. Já Cho, Roberts e Patten (2010) encontraram evidências de que empresas com desempenho ambiental pior, nas palavras dos autores, mostram-se significativamente mais otimistas e menos convictas do que suas contrapartes com melhor desempenho, destacando informações favoráveis e aspectos positivos de suas atividades. Dessa maneira, essas empresas apresentam um maior cuidado com o tom empregado em seus relatórios. Cormier, Ledoux e Magnan (2011) investigaram a relação entre as informações sociais e ambientais divulgadas na redução da assimetria informacional entre gestores e investidores.

Dessa forma, é oportuno destacar que a qualidade da divulgação voluntária pode ser questionada, especialmente considerando a ausência de auditoria sobre seu conteúdo. De acordo com Guay e Verrecchia (2007, apud Murcia \& Santos, 2009, p.4), “[...]o gestor agirá estrategicamente de acordo com seu próprio interesse, o que na maioria dos casos é a divulgação de informações boas acerca da empresa, e a não-divulgação de informações ruins". Contudo, “[...]o usuário racional interpreta a informação não divulgada como uma informação negativa, não favorável" (Verrecchia, 2001, apud Murcia \& Santos, 2009, p. 4). A afirmativa decorre da percepção dos investidores de que o gestor possui determinada informação não divulgada. A interpretação dessa ausência da informação leva a crer que seu conteúdo é negativo, o que diminuirá a confiança do investidor, com efeitos sobre o valor das ações da companhia.

\section{METODOLOGIA DA PESQUISA}

Esta pesquisa teve enfoque exploratório, de modo a buscar atingir uma visão preliminar geral do tema sob investigação, mediante a aplicação, quanto aos procedimentos caracteriza-se um experimento com uma abordagem predominantemente qualitativa.

\subsection{Seleção da companhia para elaboração do experimento}

O caso que serviu de base para o experimento foi elaborado a partir de dados da empresa Celulose Irani S.A., atuante no setor de papel e celulose, com ações negociadas na Bovespa, cujas notas explicativas às demonstrações contábeis do exercício 2008 apresentavam informações substanciais relacionadas ao meio ambiente. $\mathrm{O}$ instrumento de pesquisa aplicado está baseado na pesquisa de Alves e Borba (2009), a qual, por sua vez, utilizou, em parte, a metodologia adotada em Milne e Patten (2002).

Revista de Gestão Social e Ambiental - RGSA, São Paulo, v. 6, n. 3, p. 168-182, set./dez. 2012. 
O setor de atuação da companhia (papel e celulose) foi selecionado em decorrência da sua potencialidade de risco ao meio ambiente. A relação completa de companhias do setor de atuação da companhia selecionada, por ramo de atuação, conforme consulta ao sítio da Bovespa pode ser obtida mediante solicitação aos autores, por e-mail.

\subsection{Instrumento de pesquisa}

A exemplo de Alves e Borba (2009), objetivando proporcionar aos participantes um conjunto homogêneo de informações, não foi divulgado o nome da empresa que serviu de base para a elaboração do caso por eles analisado. Da mesma forma, não foi informado aos participantes qual a variável objeto de observação.

$\mathrm{Na}$ realização do estudo foram utilizados dois grupos: Grupo 1 (de controle) e Grupo 2 (experimental), sendo a distribuição de elementos entre esses grupos feita de forma aleatória. $\mathrm{O}$ Grupo 2 obteve as mesmas informações do Grupo 1, acrescidas das informações de caráter ambiental, as quais constituem a variável passível de observação.

Cada participante tem acesso a um conjunto de dados composto de: a) cenário, em que se estabeleciam as diretrizes gerais do experimento; b) relatório gerencial, contendo os principais índices e as demonstrações contábeis resumidas da companhia; e, c) avaliação pós-decisão, na qual o participante deveria indicar as principais informações que influenciaram sua decisão e apresentar algumas características pessoais. Essa estrutura foi utilizada por Alves e Borba (2009) em sua pesquisa e considerada adequada às necessidades do estudo.

Buscando adaptar a pesquisa realizada por Alves e Borba (2009) com as peculiaridades deste trabalho, houve a redução das opções de investimento. Nesta pesquisa, os participantes devem indicar o investimento em uma companhia a longo prazo. Já na pesquisa de Alves e Borba (2009), os participantes deveriam indicar os investimentos de duas formas, a curto e a longo prazo. Essa mudança tomou lugar partindo-se do pressuposto de que o investimento a curto prazo tem por objetivo ganho especulativo. Nesse cenário, o principal fator que influencia a decisão é a variação da cotação das ações da companhia na bolsa de valores, o que poderia descaracterizar as decisões tomadas pelos participantes, tendo em vista o objetivo geral da pesquisa.

Com base na pesquisa de Alves e Borba (2009), foi apresentado um cenário no qual o analista era convidado por um amigo a sugerir a alocação de recursos para uma empresa, cuja carteira de investimentos está destinada a prover recursos quando da aposentadoria do amigo, portanto numa visão de longo prazo. A carteira de investimentos possuía valor de mercado de $\mathrm{R} \$$ 200.000,00, havendo disponibilidade de até $\mathrm{R} \$ 20.000,00$ em recursos para a alocação à companhia.

Para o Grupo 1 (de controle) foi aplicado o caso da companhia A, cujo relatório gerencial apresentava informações favoráveis ao desempenho ambiental da empresa. Para o Grupo 2 (experimental) foi aplicado o caso da companhia B, cujo relatório gerencial apresentava o mesmo conteúdo do caso da companhia $\mathrm{A}$, cujas informações relacionadas ao meio ambiente apresentavam alguns dados desfavoráveis para a companhia. Na avaliação pós-decisão, o analista deveria indicar as informações que influenciaram sua escolha.

Caracteriza-se por informação desfavorável uma possível contingência ambiental da companhia. No caso em análise, trata-se de uma ação do Ministério Público. Para dar ênfase à informação, o valor da possível multa foi ampliado. No relatório submetido aos sujeitos

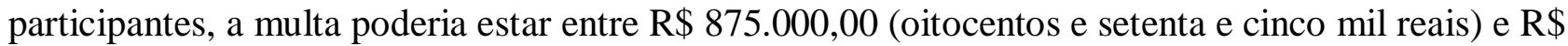
5.000.000,00 (cinco milhões de reais). No relatório original, a possível indenização poderia chegar ao valor máximo de $\mathrm{R} \$ 875.000,00$ (oitocentos e setenta e cinco mil reais).

A exemplo da pesquisa de Alves e Borba (2009), foram apresentadas, em ordem alfabética, seis informações que podem afetar a decisão do analista, além de três campos adicionais para que os participantes indiquem outras informações, conforme apresentado na figura 1. 


\begin{tabular}{|l|c|l|}
\hline Informação & \multicolumn{2}{|c|}{ Relevância para a Decisão } \\
\hline Fluxo de caixa & $, 1,2,3,4,5,6,7,8,9$ & O participante deve indicar qual a \\
\hline Ganhos por ação & $\ldots, 1,2,3,4,5,6,7,8,9$ & relevância de cada informação para \\
\hline Histórico da companhia & $, 1,2,3,4,5,6,7,8,9$ & sua decisão, numa escala de 1 a 9, \\
\hline Liquidez & $\ldots, 1,2,3,4,5,6,7,8,9$ & sendo 1 mais relevante, sem \\
\hline Questões ambientais & $-1,2,3,4,5,6,7,8,9$ & repetição de números, permitidos \\
\hline Tendências de crescimento & $\ldots, 1,2,3,4,5,6,7,8,9$ & espaços em branco. \\
\hline Outros & $\mathbf{1}, 1,2,3,4,5,6,7,8,9$ & \\
\hline
\end{tabular}

Figura 1 - Estrutura resumida da avaliação pós-decisão.

Fonte: Alves e Borba (2009).

Na primeira parte dessa avaliação, o analista deveria atribuir o número 1 à informação mais relevante para tomada de decisão, o número 2 para a segunda informação mais relevante, e assim sucessivamente. A avaliação pós-decisão termina com o analista informando alguns dados pessoais.

\subsection{Limitações da pesquisa}

A primeira limitação dessa pesquisa diz respeito ao fato de que os participantes foram submetidos a um caso hipotético que, pode prejudicar a validade dos resultados do experimento, conforme observado por Milne e Patten (2002) e Alves e Borba (2009).

Maines e Wahlen (2006) comentam que não é possível generalizar os resultados observados nesse tipo de experimento para o mundo dos negócios, por conta da influência de fatores não considerados nessa pesquisa que interagem na tomada de decisão do cotidiano do meio profissional.

Quanto a metodologia utilizada, por não haver um controle sobre os indivíduos alocados a um dos dois grupos e sua respectiva atuação profissional, os resultados obtidos não permitem uma comparação entre as respostas por grupo. Limitação relevante diz respeito também ao tamanho da amostra, que não permite a realização de testes estatísticos.

\section{APRESENTAÇÃO E ANÁLISE DOS DADOS}

Para fins de análise, com base no estudo de Alves e Borba (2009), foram considerados três níveis de relevância indicados pelos participantes da pesquisa, conforme se observa na figura 2.

\begin{tabular}{|l|c|}
\hline Nível de relevância & Grau de relevância atribuído pelos respondentes \\
\hline Alta relevância & 1,2 ou 3 \\
\hline Média relevância & 4,5 ou 6 \\
\hline Baixa relevância & 7,8 ou 9 \\
\hline
\end{tabular}

Figura 2 - Nível de relevância vs. grau de relevância

Fonte: Alves e Borba (2009)

Sendo assim, quando a informação apontada para a decisão estiver entre as três mais relevantes será considerara de alta relevância (ou altamente relevante). Para o caso de a informação ser apontada entre a quarta e a sexta mais relevante, será considerada como de média relevância. Se for apontada entre a sétima e a nona mais relevante, será tomada como de baixa relevância para decisão.

\subsection{Apresentação dos dados}

A tabela 1 apresenta o perfil dos participantes da pesquisa, ou seja, a atividade profissional que se enquadra nos três perfis considerados como amostra para o estudo. Para fins de análise dos resultados, a proporção de cada perfil entre os grupos de controle e experimental não será levada em 
consideração, considerando-se a distribuição aleatória dos sujeitos da pesquisa nos grupos objeto de estudo. É, contudo, oportuno evidenciar a proporção de cada perfil em relação à amostra total.

Tabela 1 - Perfil dos participantes da pesquisa

\begin{tabular}{lccc}
\hline & Perfil & n & \% \\
\hline Total de participantes & 24 & $100 \%$ \\
& & & \\
Analistas de investimento & 11 & $46 \%$ \\
Investidores & 7 & $29 \%$ \\
Professores & 6 & $25 \%$ \\
\hline
\end{tabular}

Fonte: Elaborado pelos autores

Aproximadamente metade dos participantes (46\%) é composta por analistas de investimento. Esta proporção pode fazer com que os resultados obtidos estejam próximos aos dados reais nas decisões de investimento, considerando que os analistas têm como atividade profissional a própria decisão de investimento.

Na tabela 2 estão apresentadas as características dos participantes da pesquisa. Na coluna A, são apresentados os dados dos sujeitos que responderam a respeito do caso da companhia $\mathrm{A}$, cuja evidenciação de informações de natureza ambiental era favorável (grupo de controle). A coluna B exibe os dados dos respondentes submetidos ao caso da companhia B, no qual as informações relacionadas ao meio ambiente eram desfavoráveis (grupo experimental).

Tabela 2 - Características dos participantes da pesquisa

\begin{tabular}{lccccc}
\hline Características & $\mathbf{A}$ & $\mathbf{\%}$ & $\mathbf{B}$ & $\mathbf{\%}$ & Total \\
\hline Total de participantes (n) & $\mathbf{1 2}$ & $100 \%$ & $\mathbf{1 2}$ & $100 \%$ & $\mathbf{2 4}$ \\
Idade (em anos) & & & & & \\
$\quad$ Menos de 30 & $\mathbf{5}$ & $42 \%$ & $\mathbf{7}$ & $58 \%$ & $\mathbf{1 2}$ \\
$30-39$ & $\mathbf{2}$ & $17 \%$ & $\mathbf{2}$ & $17 \%$ & $\mathbf{4}$ \\
40 - 49 & $\mathbf{2}$ & $17 \%$ & $\mathbf{3}$ & $25 \%$ & $\mathbf{5}$ \\
50 ou mais & $\mathbf{3}$ & $25 \%$ & & & $\mathbf{3}$ \\
Gênero & & & & & \\
Masculino & $\mathbf{1 1}$ & $92 \%$ & $\mathbf{1 1}$ & $92 \%$ & $\mathbf{2 2}$ \\
Feminino & $\mathbf{1}$ & $8 \%$ & $\mathbf{1}$ & $8 \%$ & $\mathbf{2}$ \\
Maior grau de instrução & & & & & \\
Ensino superior & $\mathbf{7}$ & $58 \%$ & $\mathbf{7}$ & $58 \%$ & $\mathbf{1 4}$ \\
Especialização & $\mathbf{1}$ & $8 \%$ & $\mathbf{2}$ & $17 \%$ & $\mathbf{3}$ \\
Mestrado & $\mathbf{3}$ & $25 \%$ & $\mathbf{1}$ & $8 \%$ & $\mathbf{4}$ \\
Outro (Doutorado) & $\mathbf{1}$ & $8 \%$ & $\mathbf{2}$ & $17 \%$ & $\mathbf{3}$ \\
Experiência profissional (em anos) & & & & & \\
$\quad$ Nenhum & & $0 \%$ & & $0 \%$ & $\mathbf{0}$ \\
Menos de dois & & $0 \%$ & $\mathbf{1}$ & $8 \%$ & $\mathbf{1}$ \\
Dois a cinco & $\mathbf{4}$ & $33 \%$ & $\mathbf{4}$ & $33 \%$ & $\mathbf{8}$ \\
Cinco a dez & $\mathbf{1}$ & $8 \%$ & $\mathbf{4}$ & $33 \%$ & $\mathbf{5}$ \\
Mais de dez & $\mathbf{7}$ & $58 \%$ & $\mathbf{3}$ & $25 \%$ & $\mathbf{1 0}$ \\
Experiência pessoal em decisões de investimento & & & & & \\
Nenhuma & $\mathbf{1}$ & $8 \%$ & & $0 \%$ & $\mathbf{1}$ \\
Pouca & $\mathbf{4}$ & $33 \%$ & $\mathbf{2}$ & $17 \%$ & $\mathbf{6}$ \\
Moderada & $\mathbf{4}$ & $33 \%$ & $\mathbf{4}$ & $33 \%$ & $\mathbf{8}$ \\
Considerável & $\mathbf{2}$ & $17 \%$ & $\mathbf{5}$ & $42 \%$ & $\mathbf{7}$ \\
Larga & $\mathbf{1}$ & $8 \%$ & $\mathbf{1}$ & $8 \%$ & $\mathbf{2}$ \\
\hline
\end{tabular}

Fonte: Elaborado pelos autores 
De acordo com a tabela 2, metade dos participantes possui menos de trinta anos. Trata-se de uma amostra predominantemente jovem, em que $88 \%$ dos sujeitos têm idade até quarenta e nove anos. No que se refere ao gênero dos respondentes, a pesquisa foi respondida quase que na sua totalidade por homens (92\%). Quanto ao grau de instrução, o nível predominante é o ensino superior, com 58\% dos participantes. Em relação à experiência profissional, observa-se a ocorrência de profissionais com, pelo menos, dois anos de atuação (96\%), sendo que $42 \%$ possuem mais de dez anos de experiência profissional. Por fim, quanto à experiência pessoal em decisões de investimento, houve certo equilíbrio entre as opções "pouca", "moderada" e "considerável" experiência: $25 \%, 33 \%$ e $29 \%$, respectivamente.

Nas figuras 3 e 4, cabe esclarecer que o conjunto "outros" é relativo às informações acrescentadas pelos respondentes nos campos próprios da avaliação pós-decisão. Também é preciso destacar que a quantidade de informações selecionadas pelos participantes como sendo relevantes para sua tomada de decisão, não foram uniformes e variaram de três a nove informações selecionadas. Essa configuração ocorreu em razão da orientação que o pesquisador passou aos sujeitos do estudo, segundo a qual estes deveriam, na avaliação pós-decisão, identificar apenas os itens que realmente afetaram suas decisões.

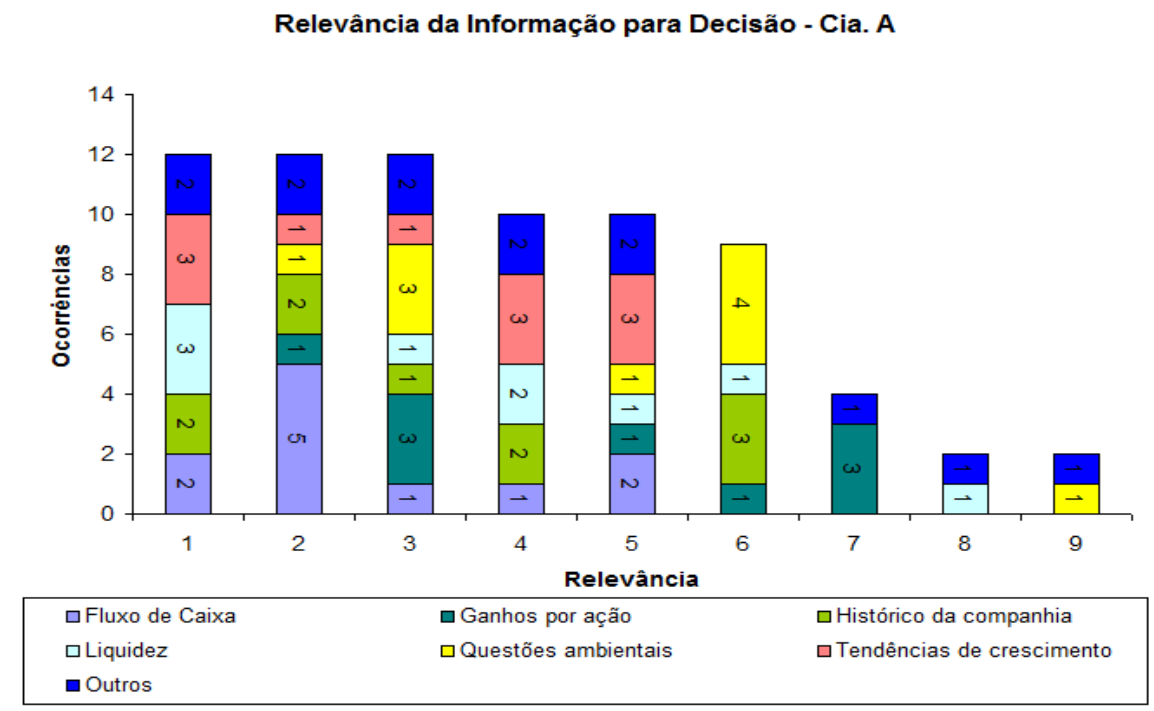

Figura 3 - Relevância da informação para decisão - companhia A

Fonte: Elaborado pelos autores

Na figura 3, representando a relevância atribuída pelos sujeitos que analisaram o caso da companhia A à informação contábil ambiental para a tomada de decisão, considerando os três maiores graus de relevância, o fluxo de caixa é apontado como a informação mais relevante na tomada de decisão dos participantes, apresentando oito ocorrências. A opção "outros" foi a segunda informação mais apontada pelos respondentes entre as três mais relevantes (seis ocorrências), sendo que nesta opção, três participantes apontaram o endividamento como sendo um dos três indicadores que mais afetaram a sua decisão. Por sua vez, a informação contábil ambiental foi escolhida por um terço dos respondentes (quatro ocorrências) como uma das três informações mais relevantes à tomada de decisão.

A figura 3 destaca a relevância atribuída à informação contábil ambiental para a tomada de decisão, na percepção dos sujeitos que analisaram o caso da companhia B. 


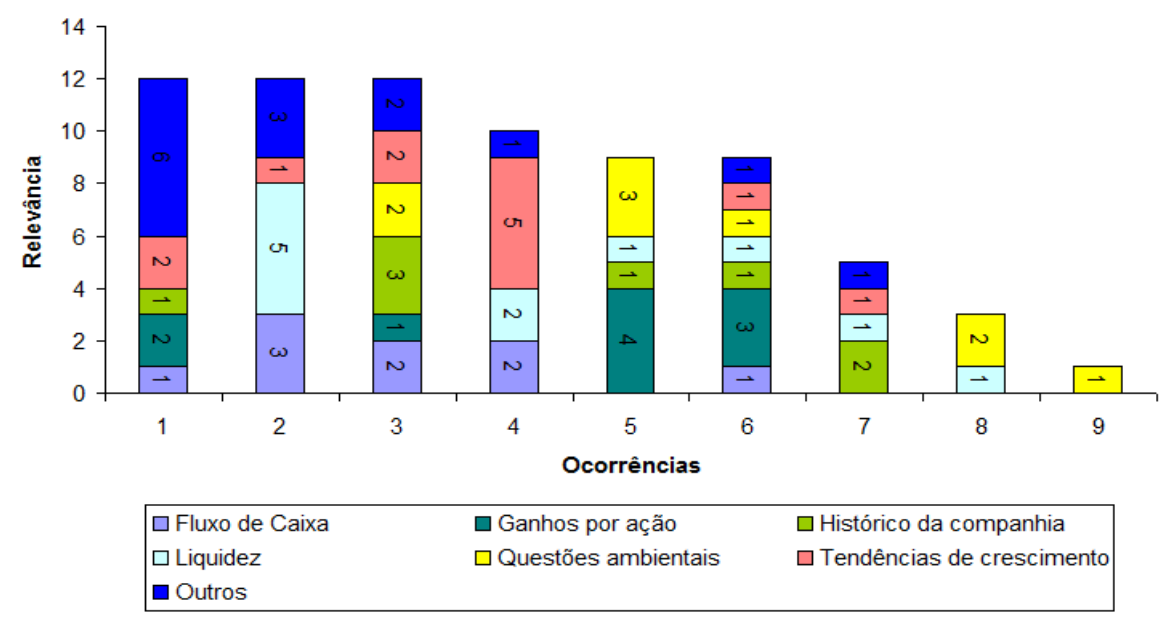

Figura 4 - Relevância da informação para decisão - companhia B

Fonte: Elaborado pelos autores

De acordo como a figura 4, considerando os três maiores graus de relevância, tem-se a informação "outros" com onze ocorrências, sendo que os participantes apontaram, assim como no caso da companhia A, por três vezes, o endividamento entre as informações de alta relevância. Outra informação que se destacou entre uma das três mais relevantes, apontada no campo "outros", foi o Ebitda (duas ocorrências). O fluxo de caixa é escolhido em seis ocorrências, como sendo um dos três mais relevantes. No que se refere à informação ambiental, apresentam-se duas ocorrências entre as três informações que mais afetaram a decisão dos participantes. A tabela 3 apresenta a relevância da informação contábil ambiental indicada pelos participantes da pesquisa.

Tabela 3 - Grau de relevância da informação ambiental para decisão de investimento

\begin{tabular}{ccccccc}
\hline $\begin{array}{c}\text { Grau de relevância da } \\
\text { informação ambiental }\end{array}$ & \multicolumn{2}{c}{ Companhia A } & \multicolumn{2}{c}{ Companhia B } & \multicolumn{2}{c}{ Total } \\
\cline { 2 - 7 } & $\mathbf{n}$ & $\mathbf{\%}$ & $\mathbf{n}$ & $\mathbf{\%}$ & $\mathbf{n}$ & $\mathbf{\%}$ \\
\hline 1 & 1 & $8,3 \%$ & & & 1 & $4,2 \%$ \\
3 & 3 & $25,0 \%$ & 2 & $16,7 \%$ & 5 & $20,8 \%$ \\
4 & & & & & & \\
5 & 1 & $8,3 \%$ & 3 & $25,0 \%$ & 4 & $16,7 \%$ \\
6 & 4 & $33,3 \%$ & 1 & $8,3 \%$ & 5 & $20,8 \%$ \\
7 & 1 & $8,3 \%$ & 3 & $25,0 \%$ & 4 & $16,7 \%$ \\
Não utilizada para decisão & 2 & $16,7 \%$ & 3 & $25,0 \%$ & 5 & $20,8 \%$ \\
\hline
\end{tabular}

Fonte: Elaborado pelos autores

Os resultados apresentados na tabela 3 possuem semelhanças com os resultados obtidos por Alves e Borba (2009) em seu experimento. Na percepção de seis participantes (25\%), a informação ambiental é altamente relevante, enquanto no estudo de Alves e Borba (2009) essa proporção foi de $22 \%$. Para nove respondentes $(38 \%)$, a variável foi considerada entre os graus quatro e seis de relevância, destacando, desta forma, que a informação contábil ambiental possui papel de média relevância nas decisões de investimento. Na pesquisa de Alves e Borba (2009), 33\% dos analistas escolheram o dado como de média relevância.

As diferenças ficam em relação à baixa relevância, onde a tabela 3 , destaca que 4 participantes (17\%) escolheram a informação como de baixa relevância, enquanto no estudo de Alves e Borba (2009), essa proporção esteve em 3\%. Outra diferença encontrada nos resultados é no que se refere à relevância da variável ambiental na decisão de investimento, enquanto neste 
estudo 19 respondentes (79\%) apontaram a informação como relevante na sua tomada de decisão, nos resultados obtidos por Alves e Borba (2009), a proporção foi de 59\%. Os resultados da pesquisa também apresentam que $21 \%$ (5 ocorrências) dos participantes não consideraram a informação relevante nas suas decisões, enquanto Alves e Borba (2009) apresentaram 40,63\%, ou seja, quase o dobro da proporção encontrada neste experimento.

Na figura 5, estão representados os níveis de relevância da informação contábil ambiental na decisão de investimento, de acordo com os participantes da pesquisa. De acordo com a figura 5 , pode-se perceber que a informação contábil ambiental é predominantemente de média relevância para os participantes da pesquisa, sendo que nove pessoas (38\%) destacaram a variável entre os graus quatro e seis de relevância.

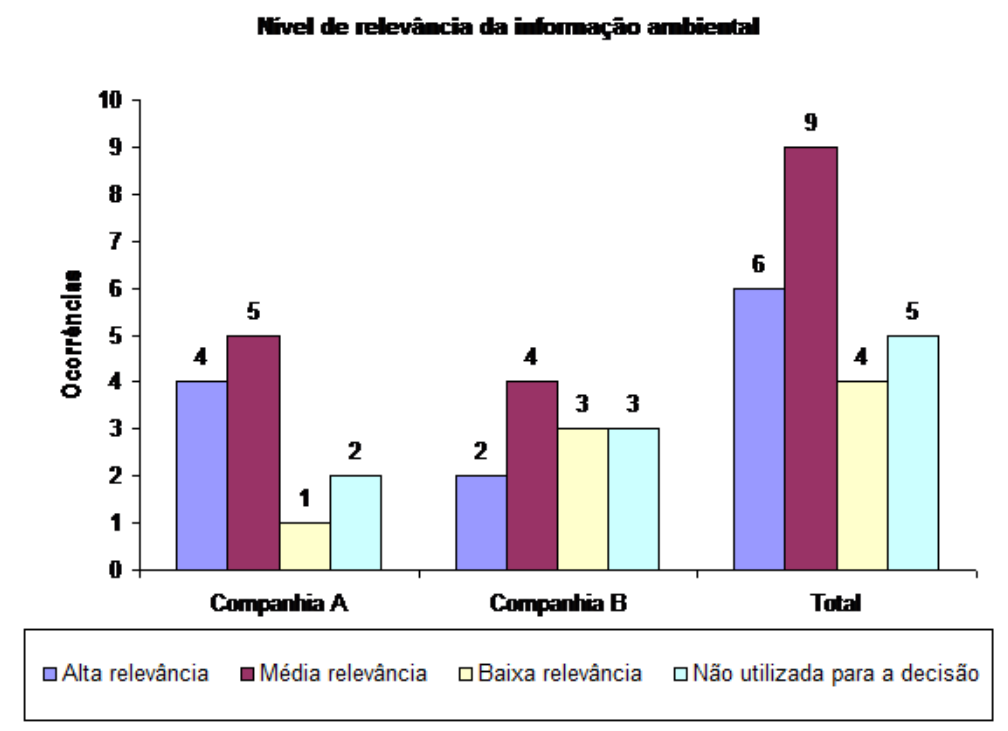

Figura 5 - Nível de relevância da informação contábil ambiental

Fonte: Elaborado pelos autores

Pode-se destacar, para aqueles que analisaram a companhia A, que um terço (33\%) dos participantes apontaram a informação ambiental como altamente relevante. A possível explicação pode estar no fato de a informação contábil ser de caráter favorável, ou seja, a evidenciação relacionada a este tema vem destacando pontos positivos da companhia no que concerne ao meio ambiente. Porém esta afirmação não é uma certeza, tendo em vista que os participantes não foram submetidos aos dois casos. A justificativa apresentada nos campos próprios da avaliação pósdecisão não permite considerações conclusivas. A realização de uma entrevista com os respectivos sujeitos que a avaliaram desta forma, poderia fornecer informações mais amplas, porém, como o acesso aos participantes foi bastante limitado, esta possibilidade não foi levantada pelo pesquisador.

\subsection{Análises adicionais}

Foi possível perceber que, quando os participantes foram submetidos ao caso da companhia A, em que a variável ambiental trazia dados favoráveis do relacionamento da empresa com o meio ambiente, a informação contábil ambiental desempenhou papel de maior relevância para a decisão. Comparativamente, nos casos onde os sujeitos foram submetidos à análise dos relatórios da companhia B, cujo conteúdo da informação ambiental trazia aspectos desfavoráveis desse relacionamento, não foi atribuída à informação contábil ambiental um grau elevado de relevância para a decisão.

Deve-se destacar o fato de que a informação contábil ambiental não foi considerada por nenhum participante da pesquisa, seja no grupo de controle (companhia A) ou no grupo 
experimental (companhia B), como sendo a informação mais relevante para sua decisão de investimento. Esse fato repete as evidências encontradas em Alves e Borba (2009).

A tabela 4 apresenta a média de investimento sugerido para as companhias A e B, de acordo com nível de relevância da informação ambiental.

Tabela 4 - Média de investimento nas companhias A e B, de acordo com o nível de relevância da informação contábil ambiental

\begin{tabular}{|c|c|c|c|c|}
\hline \multirow[b]{2}{*}{ Relevância } & \multicolumn{2}{|r|}{ Companhia A } & \multicolumn{2}{|r|}{ Companhia B } \\
\hline & $\mathbf{n}$ & Investimento médio & $\mathbf{n}$ & Investimento médio \\
\hline$\overline{\text { Alta }}$ & 4 & $6.000,00$ & 2 & $15.000,00$ \\
\hline Média & 5 & $5.600,00$ & 4 & $5.000,00$ \\
\hline Baixa & 1 & - & 3 & $5.666,67$ \\
\hline Não relacionada & 2 & $5.000,00$ & 3 & $1.666,67$ \\
\hline
\end{tabular}

Fonte: Elaborado pelos autores

Considerando os dados apresentados na tabela 4, pode-se verificar que no caso onde os participantes apontaram a informação ambiental como altamente relevante, nos sujeitos do grupo experimental (companhia B), o investimento médio foi muito superior ao investimento médio dos participantes do grupo de controle (companhia A). O dado mostra que embora a companhia B tenha apresentado algumas informações negativas acerca do seu desempenho ambiental, quando estas informações foram consideradas altamente relevantes, o investimento foi alto em relação ao valor disponível para aplicação. Por meio das justificativas fornecidas pelos respondentes na avaliação pós-decisão, não se pode chegar a considerações conclusivas em relação ao dado. Além disso, outras informações, que não a variável ambiental, influenciaram nas decisões de quanto investir na companhia.

O investimento médio foi maior entre os sujeitos do grupo experimental (companhia B), que teve como média de investimento, R\$ 6.000,00. Enquanto na companhia A, a média foi de R\$ 5.166,66. Quanto ao investimento médio dos participantes que apontaram a evidenciação ambiental como relevante na sua tomada de decisão, para a companhia A, o valor foi de $\mathrm{R} \$ 5.200,00$ e na companhia B, a média foi de R $\$ 7.444,44$.

É oportuno destacar que o valor total captado de recursos pela companhia A, foi de R\$ $62.000,00$, enquanto a companhia B captou $\mathrm{R} \$ 72.000,00$. Considerando apenas os respondentes que destacaram que a informação ambiental influenciou nas duas decisões, a companhia A teve captação de $\mathrm{R} \$ 52.000,00$, já a companhia $\mathrm{B}$, captou $\mathrm{R} \$$ 67.000,00.

A figura 6 apresenta as justificativas dos participantes em relação à informação contábil ambiental, quando esta foi indicada entre as três informações mais relevantes para as decisões, bem como o investimento sugerido em cada caso. É oportuno ressaltar que os respondentes da pesquisa tinham a disposição três campos, na avaliação pós-decisão, para suas considerações a respeito das três informações que mais afetaram sua decisão. 


\begin{tabular}{|c|c|c|c|}
\hline Cia & $\begin{array}{l}\text { Relevância da } \\
\text { informação } \\
\text { ambiental para } \\
\text { decisão }\end{array}$ & $\begin{array}{c}\text { Investimento } \\
\text { sugerido (R\$) }\end{array}$ & Justificativa apresentada \\
\hline A & 3 & - & $\begin{array}{l}\text { "Podem existir riscos de contingências ambientais que não foran } \\
\text { provisionadas e caso a empresa venha sofrer uma possível multa } \\
\text { é provável que nem possua caixa para pagá-la." }\end{array}$ \\
\hline A & 2 & $4.000,00$ & $\begin{array}{l}\text { "Questões ambientais são cada vez mais relevantes } \\
\text { principalmente em alguns setores específicos da economia, com } \\
\text { é o caso da companhia. Torna-se um diferencial muit } \\
\text { competitivo." }\end{array}$ \\
\hline A & 3 & $10.000,00$ & $\begin{array}{l}\text { "Estamos caminhando ou já inseridos em uma nova realidad } \\
\text { empresarial, onde o consumidor dos produtos e serviços está cad } \\
\text { vez mais preocupado com a atividade meio da empresa e nã } \\
\text { somente a fim (produto acabado), os processos e como } \\
\text { companhia se relaciona com os recursos que utiliza na produçãa } \\
\text { de suas atividades, se torna objeto do mercado, onde o client } \\
\text { tende a valorizar e isso se reflete nas ações e na marca d } \\
\text { companhia." }\end{array}$ \\
\hline A & 3 & $10.000,00$ & $\begin{array}{l}\text { "Particularmente com relação ao setor da economia, onde est } \\
\text { inserido a companhia (papel e celulose), é fundamental uma bo } \\
\text { política de proteção ambiental, já que o tema ambiental está en } \\
\text { evidência em todo o mundo. Certamente, se ela souber gerenciar } \\
\text { questão ambiental, ela terá retorno junto aos clientes } \\
\text { investidores. Seria um marketing para alavancar suas vendas." }\end{array}$ \\
\hline B & 3 & $10.000,00$ & $\begin{array}{l}\text { "As questões ambientais pesaram positivamente na avaliação d } \\
\text { empresa, visto que ela cumpre todas as normas ambientais } \\
\text { mostra grande preocupação com o assunto. Visto também } \\
\text { segmento que ela atua, pode ser beneficiada." }\end{array}$ \\
\hline B & 3 & $20.000,00$ & $\begin{array}{l}\text { "O setor de atuação da empresa tem forte impacto no mercad } \\
\text { atual, principalmente no tange a meio ambiente, cuja gestã } \\
\text { ambiental da empresa mostra preocupação com busca constant } \\
\text { de melhorias. O mercado atual vê com bons olhos esse tipo d } \\
\text { comportamento empresarial, principalmente os investidore } \\
\text { internacionais que na hora de direcionarem os seus recursos par } \\
\text { aplicações, buscam empresas que além de serem rentáveis } \\
\text { estáveis, tenham reconhecimento social e ambiental, o que é } \\
\text { caso em questão." }\end{array}$ \\
\hline
\end{tabular}

Figura 6- Justificativa associada à relevância da informação ambiental e investimento sugerido

Fonte: Elaborado pelos autores

Por meio da análise das justificativas apresentadas pelos participantes da pesquisa, pode-se perceber, de forma geral, que a relevância das informações de natureza ambiental está associada à importância destas questões em meio à sociedade contemporânea e ao mercado. Além disso, as considerações dos respondentes destacam que o comportamento da empresa, no que tange a sua relação com o meio ambiente, quando positiva, pode se tornar um diferencial competitivo no mercado e, consequentemente, a valorização das suas ações.

Destaca-se também, que nas explicações fornecidas pelos participantes do grupo experimental (companhia B), onde a evidenciação ambiental da companhia apresentava uma possível contingência, ou seja, uma informação desfavorável do seu desempenho ambiental, a visão dos participantes foi positiva em relação à postura da empresa quanto ao meio ambiente. A possível explicação está no fato de que, além da informação negativa divulgada, o relatório trazia algumas informações da posição da empresa quanto ao meio ambiente, em que se apresentavam aspectos favoráveis de sua atuação ambiental. 
Outro ponto a ser ressaltado está na justificativa apresentada por um dos sujeitos submetidos ao caso da companhia A (grupo de controle), onde o relatório gerencial não evidenciava a possível contingência constante no relatório da companhia B. A consideração fornecida por este participante é de que a companhia poderia possuir possíveis contingências. Mesmo com as informações não evidenciadas, o participante considerou o fato como passível de existir. Uma possível explicação ao acontecido pode ser encontrada nas seções 2.1 e 2.2 , onde constam algumas considerações referentes à não evidenciação de informações negativas.

\subsection{Análises comparativas com outras pesquisas}

Como visto, esta pesquisa está baseada no estudo de Alves e Borba (2009). Enquanto o autor aplicou o seu experimento junto a estudantes de pós-graduação como sub-rogados de analistas de mercado, esta pesquisa teve como amostra, analistas de investimento, investidores e professores de finanças. É oportuno apresentar uma comparação na composição das amostras desses dois estudos, como se faz na tabela 5 .

Tabela 5 - Comparação entre este estudo e Alves e Borba (2009)

\begin{tabular}{|c|c|c|c|c|}
\hline Características & Alves e Borba (2009) & $\%$ & Esta pesquisa & $\%$ \\
\hline Total de participantes (n) & 32 & $100 \%$ & 24 & $100 \%$ \\
\hline \multicolumn{5}{|l|}{ Idade (em anos) } \\
\hline Menos de 30 & 14 & $44 \%$ & 12 & $50 \%$ \\
\hline $30-39$ & 14 & $44 \%$ & 4 & $17 \%$ \\
\hline $40-49$ & 3 & $9 \%$ & 3 & $13 \%$ \\
\hline 50 ou mais & 1 & $3 \%$ & 5 & $21 \%$ \\
\hline \multicolumn{5}{|l|}{ Gênero } \\
\hline Masculino & 18 & $56 \%$ & 22 & $92 \%$ \\
\hline Feminino & 14 & $44 \%$ & 2 & $8 \%$ \\
\hline \multicolumn{5}{|l|}{ Maior grau de instrução } \\
\hline Ensino superior & & & 14 & $58 \%$ \\
\hline Especialização & 11 & $34 \%$ & 3 & $13 \%$ \\
\hline Mestrado & 21 & $66 \%$ & 4 & $17 \%$ \\
\hline Doutorado & & & 3 & $13 \%$ \\
\hline \multicolumn{5}{|l|}{ Experiência profissional (em anos) } \\
\hline Menos de dois & 2 & $6 \%$ & 1 & $4 \%$ \\
\hline Dois a cinco & 8 & $25 \%$ & 8 & $33 \%$ \\
\hline Cinco a dez & 11 & $34 \%$ & 5 & $21 \%$ \\
\hline Mais de dez & 11 & $34 \%$ & 10 & $42 \%$ \\
\hline \multicolumn{5}{|l|}{$\begin{array}{l}\text { Experiência pessoal em decisões de } \\
\text { investimento }\end{array}$} \\
\hline Nenhuma & 4 & $13 \%$ & 1 & $4 \%$ \\
\hline Pouca & 16 & $50 \%$ & 6 & $25 \%$ \\
\hline Moderada & 10 & $31 \%$ & 8 & $33 \%$ \\
\hline Considerável & 2 & $6 \%$ & 7 & $29 \%$ \\
\hline Larga & - & - & 2 & $8 \%$ \\
\hline
\end{tabular}

Fonte: Elaborado pelos autores

Pode-se perceber, de acordo com a tabela 5, algumas similaridades entre as amostras. Primeiramente, na idade dos participantes, sendo as duas amostras compostas, em sua maioria, por jovens com menos de quarenta anos. Outra semelhança está na experiência profissional dos respondentes das duas pesquisas, em que ambas contam com sujeitos com mais de dois anos de atividade. 
Quanto às diferenças encontradas, destaca-se o gênero dos participantes: enquanto a pesquisa de Alves e Borba (2009) apresenta um equilíbrio entre os respondentes, neste trabalho a amostra é majoritariamente composta por representantes do gênero masculino (92\%). No que se refere ao grau de instrução, este experimento possui mais da metade dos participantes (58\%) com o ensino superior. Outro fator a ser considerado é a experiência pessoal dos participantes em decisões de investimento: nesta pesquisa observa-se um equilíbrio entre os respondentes, enquanto na amostra de Alves e Borba (2009), a metade possuía pouca experiência em decisões de investimento.

A tabela 6 apresenta um resumo da relevância da informação contábil ambiental para a decisão de investimento em uma companhia, sob a perspectiva de quatro pesquisas distintas. É preciso pontuar, entretanto, uma diferença entre os outros três estudos e esta pesquisa. Neste experimento, os relatórios da companhia apresentam informações favoráveis ou desfavoráveis em relação à variável ambiental. As outras três pesquisas, por sua vez, manipulavam a variável ambiental, de modo que os relatórios apresentavam informações reduzidas ou ampliadas acerca do desempenho ambiental da companhia. Nesses estudos, os participantes tomaram duas decisões de investimento (longo prazo e curto prazo), enquanto nesta pesquisa, a opção temporal é apenas uma (longo prazo). Assim, a tabela 6 apresenta, exclusivamente, as respostas relacionadas com as decisões de investimento em longo prazo das quatro pesquisas.

Tabela 6 - Comparação sobre a relevância da informação contábil ambiental sob perspectiva de diferentes sujeitos

\begin{tabular}{|c|c|c|c|c|c|c|c|c|}
\hline Pesquisa & \multicolumn{2}{|c|}{$\begin{array}{l}\text { Milne e Patten } \\
\text { (2002) }\end{array}$} & \multicolumn{2}{|c|}{$\begin{array}{l}\text { Liyanarachchi e } \\
\text { Milne (2005) }\end{array}$} & \multicolumn{2}{|c|}{$\begin{array}{l}\text { Alves e Borba } \\
\text { (2009) }\end{array}$} & \multicolumn{2}{|c|}{ Esta pesquisa } \\
\hline Sujeitos (quantidade/país) & \multicolumn{2}{|c|}{$\begin{array}{c}\text { Analistas } \\
\text { (76/Estados Unidos } \\
\text { da América) }\end{array}$} & \multicolumn{2}{|c|}{$\begin{array}{c}\text { Estudantes de } \\
\text { Contabilidade (51/ } \\
\text { Nova Zelândia) }\end{array}$} & \multicolumn{2}{|c|}{$\begin{array}{c}\text { Estudantes de } \\
\text { Pós-Graduação } \\
\text { (32/Brasil) }\end{array}$} & \multicolumn{2}{|c|}{$\begin{array}{c}\text { Analistas, } \\
\text { investidores e } \\
\text { professores } \\
(24 / \text { Brasil })\end{array}$} \\
\hline Entre as três mais relevantes & 8 & $63 \%$ & 4 & $48 \%$ & 7 & $22 \%$ & 6 & $5 \%$ \\
\hline $\begin{array}{l}\text { Entre a quarta e a nona mais } \\
\text { relevantes }\end{array}$ & 0 & $26 \%$ & 4 & $28 \%$ & 2 & $38 \%$ & 3 & $54 \%$ \\
\hline $\begin{array}{l}\text { Não relacionada pelos } \\
\text { participantes }\end{array}$ & 8 & $11 \%$ & 2 & $24 \%$ & 3 & $41 \%$ & 5 & $21 \%$ \\
\hline
\end{tabular}

Fonte: Elaborado pelos autores

Percebe-se que, em todos os estudos apresentados, a informação contábil ambiental foi considerada relevante para tomada de decisão de investimento. A maior semelhança encontrada com este estudo está ligada à alta relevância atribuída à informação contábil ambiental pelos participantes da pesquisa de Alves e Borba (2009), onde a proporção se assemelha aos resultados aqui encontrados (22\% e $25 \%$, respectivamente).

Os motivos para as divergências e semelhanças encontradas podem estar relacionados, como bem destaca Alves e Borba (2009), com: a) nos aspectos culturais e sociais, cuja influência na tomada de decisão em investimento é explorada em diversos estudos sobre o tema; b) nos aspectos legais de cada país pesquisado; e, c) no aspecto temporal, considerando que as pesquisas foram desenvolvidas em datas diferentes.

\section{CONCLUSÕES E RECOMENDAÇÕES}

Este trabalho teve como objetivo verificar se as informações de natureza ambiental, evidenciadas nas demonstrações contábeis e no relatório da administração, são relevantes na tomada de decisão de investimento em uma companhia. Para que se chegasse ao objetivo, este estudo foi desenvolvido a partir de um experimento baseado na pesquisa de Alves e Borba (2009). Naquela oportunidade, o autor concluiu que a informação contábil ambiental, na visão de estudantes de pósgraduação, influenciava na decisão de investimento. $\mathrm{O}$ instrumento de pesquisa foi construído com

Revista de Gestão Social e Ambiental - RGSA, São Paulo, v. 6, n. 3, p. 168-182, set./dez. 2012. 
base no modelo proposto por Alves e Borba (2009), a partir da pesquisa de Milne e Patten (2002), com dados retirados dos relatórios de uma companhia do setor de papel e celulose, com ações negociadas na Bovespa, cujo exercício social foi encerrado em 31 de dezembro de 2008.

A amostra, obtida por acessibilidade, contou com 24 participantes, sendo composta por analistas de investimento, investidores do mercado de ações e professores de finanças e mercado de capitais. Destes, dezenove sujeitos (79\%) apontaram a informação contábil ambiental como relevante para sua decisão de investimento.

Os dados encontrados na análise da pesquisa apontam que a evidenciação ambiental nas demonstrações contábeis e no relatório da administração influenciam na decisão de investimento em uma companhia. Porém, não foi possível verificar qual o grau de influência deste tipo de informação.

A realização de entrevistas com analistas de investimento e investidores seria capaz de fornecer dados mais conclusivos quanto à importância da informação contábil ambiental no cotidiano das decisões de investimento. Porém, esta hipótese não foi considerada para este estudo, pois o acesso aos participantes foi restrito e a disponibilidade destes para a realização de um estudo desta natureza não existiu no momento da aplicação do experimento. Sendo assim, este tema surge como uma sugestão para próximos trabalhos.

Quanto à alocação de recursos, os sujeitos submetidos à análise de dados da companhia B, que destacaram a informação contábil ambiental como relevante, tiveram a média de investimento superior aos respondentes que analisaram o relatório da companhia A ( $\mathrm{R} \$ 7.444,44$ e $\mathrm{R} \$ 5.200,00$, respectivamente). Percebe-se, nestes dados, que, embora a companhia B apresentasse informações desfavoráveis quanto à sua relação com o meio ambiente, o investimento médio foi superior ao da companhia A, cuja evidenciação ambiental apresentava apenas informações favoráveis. Porém, não foi possível desenvolver considerações conclusivas quanto a importância da evidenciação ambiental para essa conformação do investimento, na medida em que, como destacou Alves e Borba (2009) em sua fundamentação teórica, outras informações também influenciaram os participantes nas suas decisões de quanto aplicar na companhia.

Apesar de não utilizar métodos estatísticos, essa ausência não desqualifica os resultados encontrados. Pesquisas que obtivessem amostra maior, com número de respondentes acima de trinta para analisar cada empresa, poderiam confirmar ou refutar as evidências aqui encontradas.

$\mathrm{Na}$ avaliação pós-decisão, foram apresentadas seis informações para que os analistas escolhessem as que afetaram a sua decisão, entre outras, que eles poderiam incluir. Considerando que essas informações já inseridas no relatório podem ter induzido os participantes a escolherem alguma informação, estudos que não as indicassem podem contribuir para a ampliação do debate.

A par das considerações que limitam a extrapolação dos resultados obtidos nesta pesquisa para o "mundo real", este trabalho contribui para as discussões acerca do papel da variável ambiental no ambiente das decisões de investimento. Assim o é na medida em que buscou se aproximar do real cotidiano das decisões de investimento, especialmente considerando-se a composição da amostra utilizada.

Conforme os resultados obtidos, não foi possível concluir se a evidenciação de informações favoráveis ou desfavoráveis acerca do relacionamento da empresa com o meio ambiente possui relevância decisiva na alocação de recursos a uma companhia. Dessa forma, a investigação do tema pode ser objeto de estudos futuros.

A Contabilidade, no papel de fornecedora de informações relacionadas ao desempenho ambiental das empresas, é tema recorrente em estudos na área. Entretanto, estudos buscando mensurar a utilidade da informação contábil ambiental para as decisões de investimento são incipientes. Se o usuário externo é, invariavelmente, o usuário preferencial da Contabilidade, tornase fundamental também a identificação de suas reais necessidades de informação. Essa pesquisa buscou ouvi-los e é preciso incentivá-los a falar para que possamos interpretar o que eles efetivamente levam em conta no processo decisório. 


\section{REFERÊNCIAS}

Alencar, R.C. de., Lopes, A.B.(2005). Custo do capital próprio e nível de disclosure nas empresas brasileiras. In: Congresso USP de Controladoria e Contabilidade, 5. São Paulo. Anais....Recuperado em: 10 nov.2009, de: <http://www.congressoeac.locaweb.com.br/artigos52005>.

Alves, J. L., Borba, J. A. (2009). A relevância da informação contábil ambiental para a tomada de decisão de investimento: um estudo experimental. Contabilidade, Gestão e Governança, 12 (2), 4457.

Carneiro, J. E., De Luca, M. M. M., Oliveira, M. C. (2008). Análise das informações ambientais evidenciadas nas demonstrações financeiras das empresas petroquímicas brasileiras listadas na Bovespa. Contabilidade Vista e Revista, 19 (3), 39-67.

Cormier, D., Ledoux, M., Magnan, M. (2011). The informational contribution of social and environmental disclosures for investors. Management Decision, 49 (8), 1276-1304

Cho, C. H., Roberts, R. W., Patten, D. M.(2010). The language of US corporate environmental disclosure. Accounting, Organizations and Society, 35 (4), 431-443.

Deegan, C. (2002). The legitimising effect of social and environmental disclosures: a theoretical foundation. Accounting, Auditing \& Accountability Journal, 15, 282-311.

Ferreira, A. C. de S. (2003) Contabilidade ambiental. São Paulo: Atlas.

Hendriksen, E. S.; Van Breda, M. F. (1999). Teoria da contabilidade. São Paulo: Atlas.

Liyanarachchi, G. A., Milne, M. J. (2005). Comparing the investiment decisions of accounting practioners and students: an empirical study on the adequacy of student surrogates. Accounting Forum, 29 (2), 121-135.

Maines, L. A., Wahlem, J.M. (2006). The nature of accounting information reliability: inferences from archival and experimental research. Accounting Horizons, 20 (4), 399-425.

Milne, M.J., Patten, D.M. (2002). Securing organizational legitimacy: an experimental decision case examining the impact of environmental disclosures. Accounting, Auditing \& Accountability Journal, 15(3), 372-405.

Murcia, F. D., Santos, A. dos. (2009). Fatores determinantes do nível de disclousure voluntário das companhias abertas no Brasil. In: Congresso Internacional de Contabilidade da Anpcont, 3. São Paulo. Anais... Recuperado em 22 nov.2009, de: http://www.congressoanpcont.com.br/.

Murray, A., Sinclair, D., Power, D., Gray, R. (2006). Do financial markets care about social and environmental disclosure? Further evidence and exploration from the UK. Accounting, Auditing \& Accountability Journal, 19 (2), 228-255.

\footnotetext{
Recebido em: 29/11/2011
}

Publicado em: 21/12/2012 